\title{
Conformational distributions at the N-peptide/boxB RNA interface studied using site-directed spin labeling
}

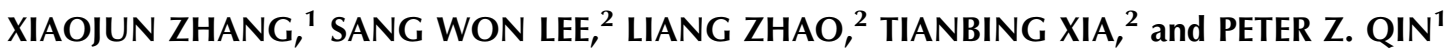 \\ ${ }^{1}$ Department of Chemistry, University of Southern California, Los Angeles, California 90089-0744, USA \\ ${ }^{2}$ Department of Molecular and Cell Biology, The University of Texas at Dallas, Richardson, Texas 75080-3021, USA
}

\begin{abstract}
In bacteriophage $\lambda$, interactions between a 22-amino acid peptide (called the $\mathrm{N}$-peptide) and a stem-loop RNA element (called boxB) play a critical role in transcription anti-termination. The $\mathrm{N}$-peptide/boxB complex has been extensively studied, and serves as a paradigm for understanding mechanisms of protein/RNA recognition. Particularly, ultrafast spectroscopy techniques have been applied to monitor picosecond fluorescence decay behaviors of 2-aminopurines embedded at various positions of the boxB RNA. The studies have led to a model in which the bound $\mathrm{N}$-peptide exists in dynamic equilibrium between two states, with peptide C-terminal fragment either stacking on (i.e., the stacked state) or peeling away from (i.e., the unstacked state) the RNA loop. The function of the N-peptide/boxB complex seems to correlate with the fraction of the stacked state. Here, the $\mathrm{N}$-peptide/boxB system is studied using the site-directed spin labeling technique, in which X-band electron paramagnetic resonance spectroscopy is applied to monitor nanosecond rotational behaviors of stable nitroxide radicals covalently attached to different positions of the $\mathrm{N}$-peptide. The data reveal that in the nanosecond regime the $\mathrm{C}$-terminal fragment of bound $\mathrm{N}$-peptide adopts multiple discrete conformations within the complex. The characteristics of these conformations are consistent with the proposed stacked and unstacked states, and their distributions vary upon mutations within the $\mathrm{N}$-peptide. These results suggest that the dynamic two-state model remains valid in the nanosecond regime, and represents a unique mode of function in the N-peptide/boxB RNA complex. It also demonstrates a connection between picosecond and nanosecond dynamics in a biological complex.
\end{abstract}

Keywords: N-peptide; boxB RNA; site-directed spin labeling; RNA/protein recognition; EPR

\section{INTRODUCTION}

RNA-protein interactions play crucial roles in cellular processes, and nature has evolved a number of recurring RNAbinding motifs to recognize diverse RNA structures (Burd and Dreyfuss 1994; Draper 1999; Yu and Gabriele 2005; Lunde et al. 2007; Cléry et al. 2008). It has been demonstrated that RNA conformations are dynamic, and such dynamics profoundly impact the diverse functions of RNAs (Al-Hashimi and Walter 2008). Consequently, RNA recognition is often achieved via induced fit or conformational capture mechanisms (Williamson 2000; Leulliot and Varani 2001). For example, the arginine-rich motif (Weiss and Narayana 1998) often interacts with viral RNAs via adaptive recognition (Patel 1999). However, the relationship

Reprint requests to: Peter Z. Qin, LJS-251, 840 Downey Way, Los Angeles, CA 90089-0744, USA; e-mail: pzq@usc.edu; fax: (213) 740-0930.

Article published online ahead of print. Article and publication date are at http://www.rnajournal.org/cgi/doi/10.1261/rna.2360610. between conformational dynamics of RNA-protein complexes and their functions is not well understood.

The interactions between the boxB RNA and bacteriophage $\lambda \mathrm{N}$ protein have been a classic paradigm in studying RNA-protein recognition. During development of bacteriophage $\lambda$, the $\mathrm{N}$ protein plays a critical role in transcription anti-termination, as $\mathrm{N}$ protein binding to a nascent mRNA stem-loop structure called boxB initiates the process of converting the RNA polymerase into a terminationresistant form (Das 1993; Greenblatt et al. 1993). The first 22 amino acids of the $\mathrm{N}$ protein (termed N-peptide) contain five arginines and constitute an arginine-rich motif, which accounts for boxB binding (Cilley and Williamson 1997; Van Gilst et al. 1997). Circular dichroism (CD) measurements indicated that the $\mathrm{N}$-peptide is disordered and only folds when bound to boxB RNA (Mogridge et al. 1998). NMR studies (Su et al. 1997; Legault et al. 1998; Schärpf et al. 2000) revealed that in the bacteriophage $\lambda$ $\mathrm{N}$-peptide/boxB complex, N-peptide adopts a bent $\alpha$-helical conformation, while the boxB pentaloop (G6A7A8A9A10) folds into a stable GNRA tetraloop with the fourth loop 
base (A9) extruded out (Fig. 1A,D,E). The stacking of Tryptophan 18 of the N-peptide on adenine 7 of the boxB pentaloop (Trp18/A7 stacking) is known to be a critical factor that affects N-peptide's biological function of transcription anti-termination (Austin et al. 2003; Xia et al. 2003a,b, 2005).

Previous studies have also revealed that the anti-termination function is drastically affected by single or double mutations at the 14 th and 15 th residues of the $\mathrm{N}$-peptide. These mutants were selected as alternative solutions for binding the boxB RNA (Barrick et al. 2001), and most of them maintain a high boxB binding affinity that is comparable to that of the wild-type N-peptide (Austin et al. 2002). However, these mutations significantly impact the functional capacity of $\mathrm{N}$ protein variants. For example, mutating the wild-type sequence of $\mathrm{K}_{14} \mathrm{Q}_{15}$ to $\mathrm{E}_{14} \mathrm{R}_{15}$ completely abolished anti-termination activity when measured in vivo (Xia et al. 2003a). Based on ultrafast time-resolved spectroscopic probing (Xia et al. 2003a, 2005), a dynamic two-state model has been proposed, which stipulates that the N-peptide/boxB complex exists in dynamic equilibrium between stacked and unstacked states (Fig. 1E). In both states, the $\mathrm{N}$-terminal fragment ( $\mathrm{N}$-fragment, residues 1-11) of the $\mathrm{N}$-peptide forms an $\alpha$-helix that inserts into the
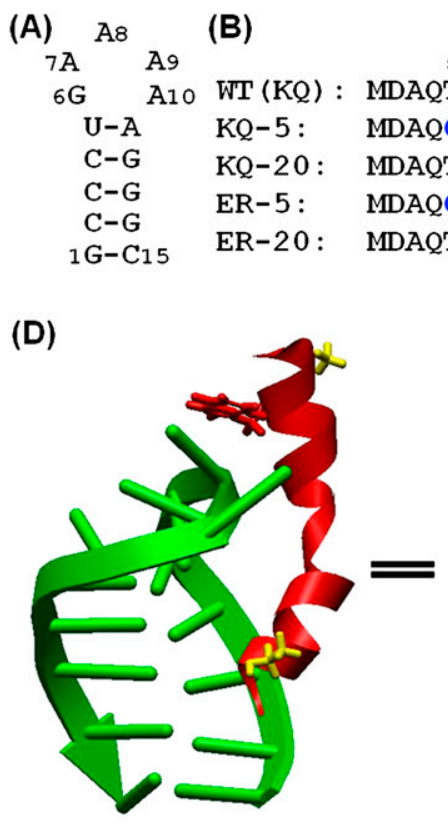

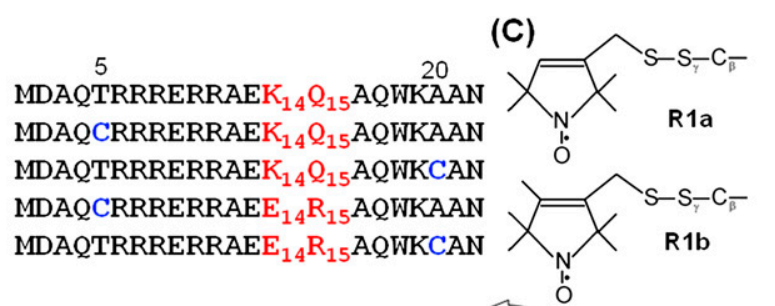

(E)

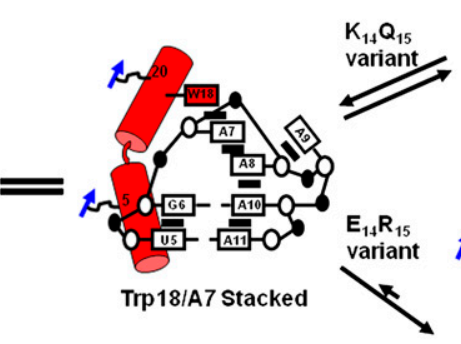

boxB RNA stem, serving as a strong anchor to provide the high-affinity. In the stacked state, presumably represented by the NMR structure of the complex (Legault et al. 1998; Schärpf et al. 2000), the C-terminal fragment (C-fragment, residues 12-22) forms an $\alpha$-helix with Trp18 stacking on A7 of the RNA loop. In the unstacked state, the C-fragment is postulated to peel away from the RNA loop and likely become unstructured. Equilibrium between these two states seems to be modulated by residues 14 and 15: The stacked state is up to $60 \%$ in the wild type (i.e., $\mathrm{K}_{14} \mathrm{Q}_{15}$ ), but reduces to at most $\sim 10 \%$ in the $\mathrm{E}_{14} \mathrm{R}_{15}$ mutant. It has been proposed that changes in the percentage of the stacked state account for the functional variations of the mutations (Xia et al. 2005). These studies suggest a dynamic recognition mode at the N-peptide/boxB protein-RNA interface, where a single stacking interaction (i.e., Trp18/A7) seems to be critical for the entire anti-termination machinery (Xia et al. 2003a,b, 2005).

The existence of at least two discrete states in the $\mathrm{N}$-peptide/boxB complex is inferred from ultrafast timeresolved spectroscopic measurements that monitor femtosecond to picosecond fluorescence decay of 2-aminopurines (2AP) incorporated in the boxB stem-loop (Xia et al. 2003a, 2005). The nature of the bound peptide structure, particularly in the unstacked state, is not clear because fluorescence signals came from the RNA portion of the complex. Preliminary CD measurements suggested that the C-terminal half of the peptide is unfolded (random coil) upon Trp18/A7 unstacking (Xia et al. 2003b). On the other hand, NMR imino proton measurements of the Trp18 within the complex indicated that the two states, if exist, are in fast-exchange at the microsecond to millisecond regime (Xia et al. 2003b). However, the two-state model has not been investigated in the nanosecond regime, which is generally believed to encompass collective motions of residues and structural elements (e.g., $\alpha$-helix) in bio-molecules.

To further our understanding of the interplay of dynamics in various timescales as well as the relationship between dynamics and function in biological systems, the N-peptide/boxB complex was studied using the technique of sitedirected spin labeling (SDSL) (Altenbach et al. 1989). In SDSL, a stable nitroxide radical is covalently attached to a specific site of a macromolecule. Behaviors of the nitroxide, monitored using electron paramagnetic resonance (EPR) spectroscopy, are used to obtain information
FIGURE 1. The bacteriophage $\lambda$ N-peptide/boxB complex. (A) Sequence and secondary structure of the boxB RNA. (B) Sequences of the N-peptides. $(C)$ Chemical structures of the Rla and R1b nitroxide probes. $(D)$ NMR structure of the N-peptide/boxB complex, with the red ribbon representing the N-peptide and the green ladder representing the boxB RNA. Three $\mathrm{N}$-peptide side-chains are rendered using the stick representation, with Trp18 (critical for antitermination function) shown in red, and Thr5 and Ala20 (spin labeling sites) shown in yellow. (E) Schematics of the dynamic two-state model, which postulates that the N-peptide/boxB complex exists in equilibrium between a Trp18/A7 stacked state and a Trp18/A7 unstacked state. With the $\mathrm{K}_{14} \mathrm{Q}_{15}$ (wild type) peptide both states are populated, while the $\mathrm{E}_{14} \mathrm{R}_{15}$ peptide tilts the equilibrium toward the unstacked state. Blue arrows indicate spin label attachment sites. 
on macromolecular structure and dynamics. SDSL has matured as a technique for probing protein structure and dynamics (Fanucci and Cafiso 2006), and has also been applied to investigate nucleic acids (Sowa and Qin 2008). However, SDSL studies of protein/RNA complexes are limited (Edwards et al. 2005; $\mathrm{Xi}$ et al. 2008; Zhang et al. 2008)

Here, two nitroxide derivatives, R1a and R1b (Fig. 1C), were attached at sites within the $\mathrm{N}$ - and $\mathrm{C}$-fragment of two $\mathrm{N}$-peptides without disrupting the native complex. Continuous-wave EPR (cwEPR $)$ spectroscopy at X-band $(\sim 9.34$ $\mathrm{GHz}$ ) was employed to monitor rotational diffusive motions (i.e., mobility) of these nitroxides in the $0.1-50 \mathrm{nsec}$ regime. The data indicate that within the bound peptide the C-fragment exists in at least two discrete conformations. These conformations show characteristics consistent with the proposed stacked and unstacked states, and distributions between these states vary according to mutations at positions 14 and 15. This suggests that the dynamic twostate model remains valid in the nanosecond regime, and is the mode of function in the N-peptide/boxB system.

\section{RESULTS}

\section{Experimental design and biochemical characterization}

Work reported here examined two N-peptides, which differ in amino acid identity at positions 14 and 15 (Fig. 1B) and represent the full spectrum of functional capacity (Barrick et al. 2001) and ultrafast dynamics characteristics (Xia et al. 2003a, 2005). The KQ peptide has the wild-type sequence (i.e., $\mathrm{K}_{14} \mathrm{Q}_{15}$ ) that is capable of supporting Trp18/A7 stacking and is fully functional in anti-termination. The ER peptide contains a $\mathrm{K}_{14} \mathrm{Q}_{15}$ to $\mathrm{E}_{14} \mathrm{R}_{15}$ mutation, which has been shown to be detrimental to Trp18/A7 stacking and anti-termination activity. However, the ER peptide binds to boxB RNA with a $K_{\mathrm{d}}$ of a few nanomolar, which is similar to that of the wild type (Table 1; Xia et al. 2003a).

For each N-peptide, spin labels were attached to two sites spanning the critical Trp18 residue (Fig. 1B): one at position 5 to assess behaviors of the $\mathrm{N}$-fragment (residues 111 ), and the other at position 20 to assess the C-fragment (residues 12-22). Labeling of two types of nitroxide, R1a and R1b (Fig. 1C), was achieved by mutating the native residue ( $\mathrm{T} 5$ or $\mathrm{A} 20$ ) to a cysteine, then coupling with it the respective nitroxide methanthiosulfonate derivatives. In the text, a particular sample is identified by the peptide name followed by nitroxide location and identity. For example, ER-5R1a designates the ER peptide with the R1a nitroxide attached to position 5.
The two labeling positions were chosen based on previous studies to minimize potential disruptions to the native conformation(s) of the N-peptide/boxB complex (Su et al. 1997). In the NMR structure of the N-peptide/boxB complex, side chains of these two positions point away from the peptide/RNA interface (Fig. 1D; Legault et al. 1998). Measured $K_{\mathrm{d}}$ values between boxB and spin-labeled $\mathrm{N}$-peptides are within an order of magnitude as compared to that of the respective unlabeled peptides, and the corresponding differences in standard state free energy change are no more than $1.1 \mathrm{kcal} / \mathrm{mol}$ (Table 1). This indicates that cysteine substitution and spin label attachment do not interfere with N-peptide/boxB complex formation. Furthermore, femtosecond time-resolved spectroscopic probing was carried out on complexes formed between cysteinesubstituted N-peptides and 2AP-labeled boxB RNA (Supplemental Fig. S1). The data indicated that these complexes exhibit fluorescence decay characteristics similar to the respective unsubstituted peptides, with the $\mathrm{K}_{14} \mathrm{Q}_{15}$ to $\mathrm{E}_{14} \mathrm{R}_{15}$ mutation giving rise to drastically different distributions of Trp18/A7 stacked and unstacked populations (Supplemental Fig. S1).

\section{X-band EPR spectrum reports on $\mathrm{N}$-peptide behaviors at the nanosecond regime}

Figure $2 \mathrm{~A}$ shows $5^{\circ} \mathrm{C}$ aqueous solution spectra of R1a attached to position 20 of the two N-peptides. In the absence of boxB RNA, each N-peptide shows a three-line spectrum with no extra features at the low-field and highfield regions, which is the characteristic of a nitroxide undergoing fast and isotropic rotational motions (Sowa and Qin 2008). We note that a cw-EPR spectrum reports on a combination of three modes of nitroxide motions (Hubbell and Altenbach 1994): overall rotational tumbling of the macromolecule (characterized by a rotational correlation time $\tau_{\mathrm{R}}$ ); torsional rotations around bonds connecting the nitroxide pyrroline ring to the macromolecule $\left(\tau_{\mathrm{i}}\right)$; and local motions of the macromolecule at and around the labeling site $\left(\tau_{\mathrm{b}}\right)$. Features of the aqueous $\mathrm{N}$-peptide 
A

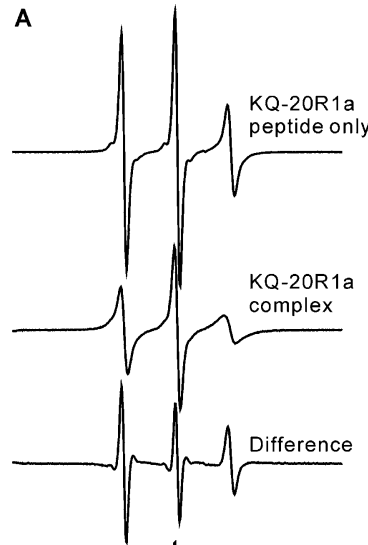

B
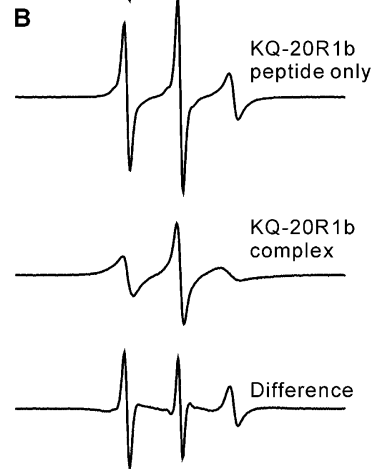
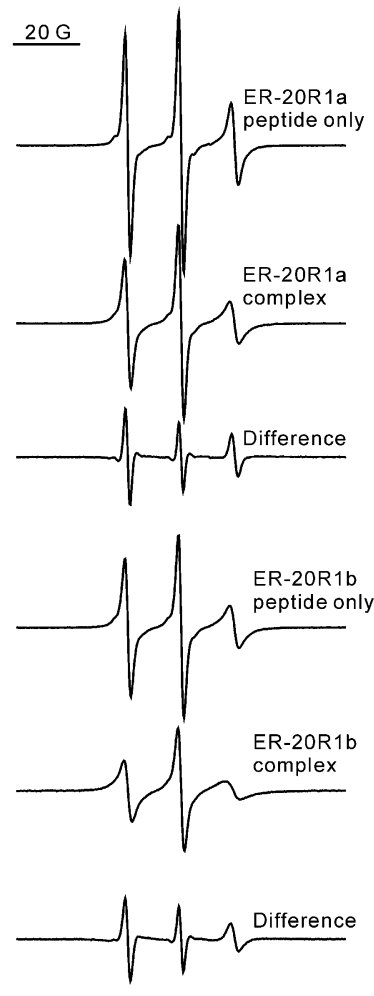

FIGURE 2. Comparison of KQ-20 and ER-20 spectra in the absence and presence of boxB RNA. Spectra were acquired at $5^{\circ} \mathrm{C}$ in aqueous solutions. Difference spectra are shown to emphasize spectral change upon boxB RNA binding. (A) Peptides labeled with R1a. (B) Peptides labeled with R1b.

spectrum (Fig. 2A) are dictated primarily by fast tumbling of the parent $\mathrm{N}$-peptide $(\mathrm{MW} \sim 2.9 \mathrm{kDa})$, which has an estimated overall rotational correlation time $\tau_{\mathrm{R}}$ of $2.6 \mathrm{nsec}$ at $5^{\circ} \mathrm{C}$ in aqueous solution based on a hydrodynamic model (Cantor and Schimmel 1980; Qin et al. 2003). In the presence of the boxB RNA, spectra of both peptides maintain the three-line feature but show clear line-broadening and amplitude-reduction (Fig. 2A). This suggests a reduction in nitroxide motions upon formation of the $\mathrm{N}$-peptide/boxB complex ( $\mathrm{MW} \sim 8 \mathrm{kDa})$.

The same pattern of line-broadening is observed in aqueous spectra of R1b-labeled peptides upon boxB RNA binding (Fig. 2B). Furthermore, each R1b spectrum shows linebroadening and amplitude-reduction as compared to the corresponding $\mathrm{R} 1 \mathrm{a}$ counterpart, indicating lower $\mathrm{R} 1 \mathrm{~b}$ mobility as compared to Rla. This is expected, as the presence of the 4- $\mathrm{CH}_{3}$ group at the pyrroline ring of $\mathrm{R} 1 \mathrm{~b}$ (Fig. 1C) restricted torsional rotations about bonds connecting the nitroxide pyrroline ring to the peptide (Columbus et al. 2001).

In addition to demonstrating complex formation with the spin-labeled $\mathrm{N}$-peptides, the aqueous solution data reveal that site-dependent motions $\left(\tau_{\mathrm{i}} / \tau_{\mathrm{b}}\right)$ of R1a and R1b probes must be comparable or slower than the uniform overall tumbling of the N-peptide, which is estimated to be

$\tau_{\mathrm{R}} \sim 2.6$ nsec. If $\left(\tau_{\mathrm{i}} / \tau_{\mathrm{b}}\right)$ motions were 10 times faster (e.g., $\sim 0.3 \mathrm{nsec}$ or $300 \mathrm{psec}$,), it would dominate the EPR spectrum, and no spectral dependence on overall molecular tumbling (i.e., macromolecular size) would be observed. This puts an upper limit of $\left(\tau_{\mathrm{i}} / \tau_{\mathrm{b}}\right) \geq 0.3 \mathrm{nsec}$, and reaffirms the notion that X-band EPR measurements assess behaviors of the N-peptide/boxB complex in the 0.3-20 nsec regime, which complements the picosecond regime previously studied by ultrafast fluorescence spectroscopy (Xia et al. 2003a, 2005).

We note that aqueous spectra of the complexes show differences between KQ-20 and ER-20 (Fig. 2), indicating that the local environment within the complex are different between the two peptides at position 20. However, EPR spectra obtained in aqueous solution are not optimal for probing site-specific features, as they are dominated by the uniform fast tumbling of the complex. Therefore, in the following studies, spectra were obtained in the presence of a cosolvent, such as Ficoll 70 (abbreviated as "Ficoll") or sucrose. The cosolvent increases solution viscosity and reduces macromolecular tumbling (i.e., larger $\tau_{\mathrm{R}}$ ), and the resulting EPR spectra are more adapted to reveal local structural and dynamic features reported by variations in site-specific nitroxide motions (i.e., $\tau_{\mathrm{i}}$ and/or $\tau_{\mathrm{b}}$ effects).

\section{Peptide $\mathrm{N}$-fragment in the complex: Low-mobility state independent of the $K_{14} Q_{15}$ to $E_{14} R_{15}$ mutation}

Figure 3 shows $5^{\circ} \mathrm{C}$ spectra of $\mathrm{N}$-peptide/boxB complex obtained in a $30 \%(\mathrm{w} / \mathrm{v})$ Ficoll solution. At position 5, which is located in the middle of the N-terminal $\alpha$-helix (Fig. 1B), identical spectra were obtained between the KQ and ER peptides using either the Rla (Fig. 3A) or the R1b probe (Fig. 3B). The R1b spectra at position 5 show clearly visible broad peaks at the low-field and a valley at the highfield region, and the measured splitting between these two extrema gives an effective hyperfine splitting $(2 \mathrm{~A})$ of 66.7 Gauss (G). These spectra features indicate an immobilized R1b probe. The 5R1a spectra (Fig. 3A), with no visible low-field and high-field extrema, show a higher mobility than R1b. The peak to peak width of the central line $\left(\Delta \mathrm{H}_{0}=2.9 \mathrm{G}\right)$ and the second moment of the spectrum $\left(<\mathrm{H}^{2}>=217.6 \mathrm{G}^{2}\right)$ are consistent with $\mathrm{R} 1$ a residing on a protein helical surface site (McHaourab et al. 1996).

Overall, the results indicate that in the N-peptide/boxB complex, the $\mathrm{N}$-fragment adopts a conformation with low mobility. Such conformation is not affected by the $E_{14} R_{15}$ mutation.

\section{Peptide C-fragment in the complex: High-mobility states that depend on the $K_{14} Q_{15}$ to $E_{14} R_{15}$ mutation}

Spectra at position 20 (Fig. 3C,D), which is C-terminal with respect to Trp18, show a number of clearly different features as compared to those at position 5 (Fig. 3A,B). The 
A

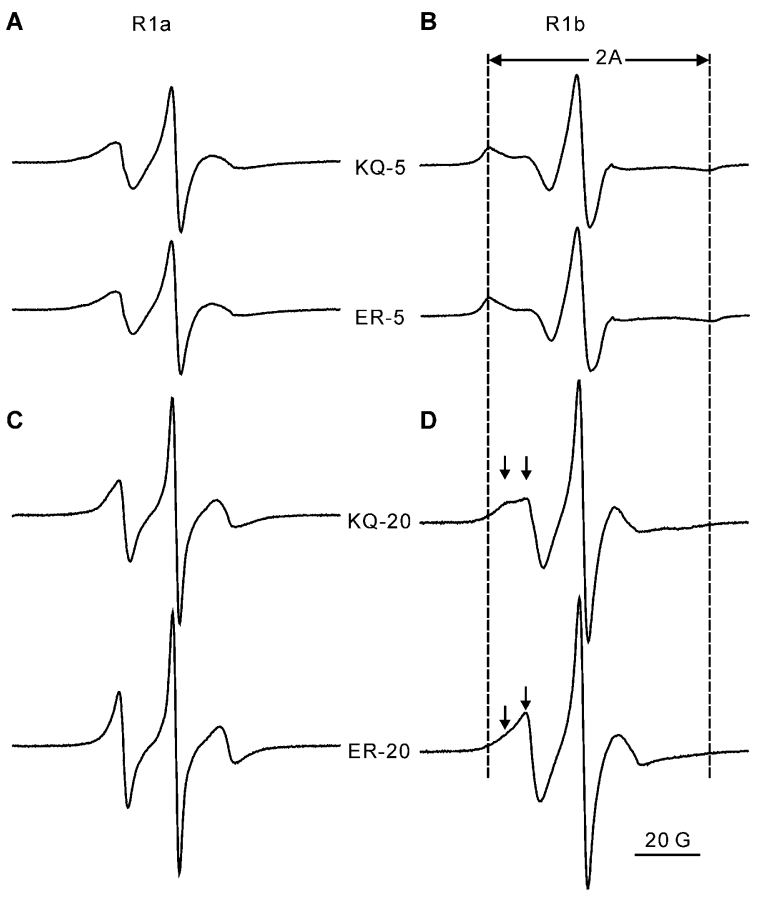

FIGURE 3. Spectra of N-peptide/boxB complexes acquired in $30 \%$ $(\mathrm{w} / \mathrm{v})$ Ficoll at $5^{\circ} \mathrm{C}$. (A) R1a labeled at position 5. (B) R1b labeled at position 5. Dashed lines mark the hyperfine splitting, and are extended to panel $D$ to aid comparisons. $(C)$ R1a labeled at position 20. (D) R1b labeled at position 20. Arrows indicate features that reveal the presence of multiple spectral components.

KQ-20R1a spectrum (Fig. 3C), while maintaining the three-line characteristics, shows a narrower central line than that of KQ-5R1a (Fig. 3A), indicating mobility at site 20 is higher than that at site 5 . Contrary to the position 5 case (Fig. 3A), 20R1a spectra change upon the $E_{14} R_{15}$ mutation (Fig. 3C). ER-20R1a shows narrower lines with higher peak amplitudes, indicating higher nitroxide mobility as compared to KQ-20R1a (Fig. 3C).

The R1b spectra recapitulate all essential features revealed by R1a. The KQ-20R1b spectrum (Fig. 3D) has a narrower center line as compared to KQ-5R1b (Fig. 3B), with its low-field and high-field extrema shifted clearly toward the center and largely decreased in amplitude. These features indicate that in the KQ peptide position 20 has a higher mobility than that at position 5. Furthermore, 20R1b spectra are clearly different between the KQ and ER peptides (Fig. 3D). Compared to KQ-20R1b, the ER-20R1b spectrum has a slightly narrower center line, its high-field extrema disappears, and the low-field extrema is depressed to a barely visible shoulder (Fig. 3D). This indicates that the $\mathrm{E}_{14} \mathrm{R}_{15}$ mutation results in an overall higher R1b mobility.

Based on the NMR structure of the N-peptide/boxB complex (Legault et al. 1998), modeling studies indicate that a nitroxide attached at position 20 of the bound peptide resides within a helical segment and has no direct contact with amino acids at positions 14 and 15 . Therefore, nitroxide internal motions (i.e., $\tau_{\mathrm{i}}$ motion) at position 20 are expected to be the same between the KQ and ER peptides, and the observed spectral variations must originate from different peptide conformations (i.e., $\tau_{\mathrm{b}}$ motion). The EPR data consequently provide the first set of direct evidence that the $\mathrm{E}_{14} \mathrm{R}_{15}$ mutation changes $\mathrm{C}$-fragment conformations within the bound N-peptide.

\section{Multiple peptide conformations at the $\mathrm{C}$-fragment}

Another distinct feature revealed by the C-fragment EPR spectra is the presence of multiple spectral components. In the low-field region of the complex spectra, KQ20-R1b clearly shows two peaks, while ER-20R1b has a shoulder (Fig. 3D, marked by arrows). This indicates existence of heterogeneous nitroxide populations. Compared to that of KQ-20R1b, the shoulder in ER-20R1b spectrum is much depressed in amplitude (Fig. 3D), suggesting that in the ER peptide the population of the low-mobility nitroxide is reduced.

The observed multiple spectral components may arise due to multiple conformations of the parent peptide that are in slow-exchange at the EPR timescale, or they may be due to multiple nitroxide side-chain configurations (rotamers) residing at the same parent peptide conformation. These two scenarios were distinguished using a recently reported osmolyte perturbation method (Galiano et al. 2009; Lopez et al. 2009; Flores Jimenez et al. 2010), in which EPR spectra obtained in Ficoll solutions (Fig. 3) were compared with those obtained in another cosolvent, namely sucrose. Solution of Ficoll has high viscosity but low osmolarity, and has been reported to exert little effect on distributions of protein conformations (Luby-Phelps et al. 1987; Zhou et al. 2008; Lopez et al. 2009). On the other hand, it has been shown that sucrose alters distributions among different protein conformations, but does not change equilibriums between nitroxide rotamers residing at the same protein conformation (Galiano et al. 2009; Lopez et al. 2009). Therefore, if multiple EPR spectral components originate from multiple protein (or peptide) conformations, one would expect spectral variations when the cosolvent is changed from Ficoll to sucrose (Lopez et al. 2009).

The osmolyte perturbation experiment requires one to match the effective viscosity experienced by the macromolecule in Ficoll and sucrose, so that only site-specific features (macromolecule conformation and/or nitroxide rotamer) give rise to spectral changes (Lopez et al. 2009). This was achieved by measuring spectra of KQ-5R1b at different concentrations of sucrose solutions, as KQ-5 is likely dominated by one peptide conformation based on previous work (Legault et al. 1998; Xia et al. 2005) and a lack of $E_{14} R_{15}$ mutation effect in our studies (Fig. 3). At $5^{\circ} \mathrm{C}$, it was found that spectrum obtained in $34 \%(\mathrm{w} / \mathrm{w})$ sucrose solution matched the best with that measured in $30 \%(w / v)$ Ficoll, 
with the effective hyperfine splitting $(2 \mathrm{~A})$ being $66.7 \mathrm{G}$ in Ficoll and $66.5 \mathrm{G}$ in sucrose, respectively (Fig. 4A). This suggests that in $34 \%(\mathrm{w} / \mathrm{w})$ sucrose and $30 \%(\mathrm{w} / \mathrm{v})$ Ficoll, the effective viscosity experienced by the $\mathrm{N}$-peptide/boxB complex is the same. This conclusion was confirmed by additional experiments using a DNA duplex containing a rigidly fused nitroxide probe (Supplemental Fig. S2).

Spectra of KQ-20R1b and ER-20R1b were then measured under the viscosity matching condition, and were found to vary between Ficoll and sucrose (Fig. 4B,C). For KQ-20R1b (Fig. 4B), the sucrose spectrum gives a significantly broader center line. The low-field region shows two peaks, with relative increases in the outer peak (representing the lowmobility component) and decreases in the inner peak (representing the high-mobility component). These spectral changes indicate an increase in low-mobility component and a reduction in high-mobility component in the sucrose solution. The same characteristics were observed for ER20R1b (Fig. 4C).

As sucrose is known to be a protecting osmolyte, it is expected to favor the more compact (less solvent accessible) state of the complex (Lopez et al. 2009), which would have a lower peptide mobility. This agrees well with the observed spectral changes at position 20 (Fig. 4B,C), and strongly

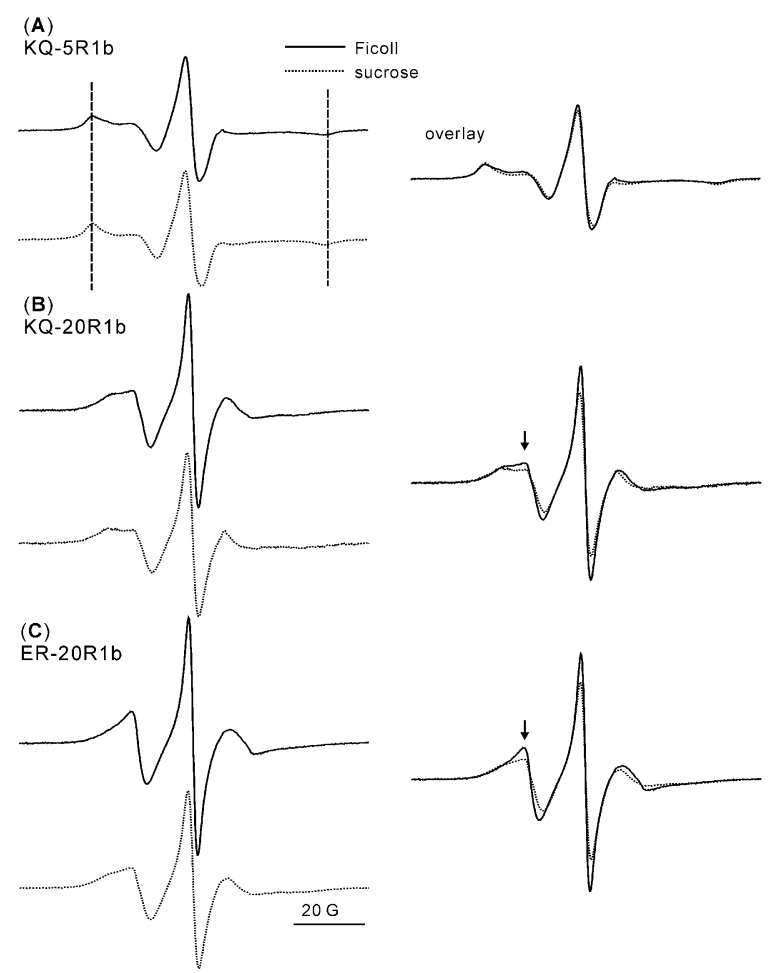

FIGURE 4. Comparisons of N-peptide/boxB complex spectra obtained in 30\% (w/v) Ficoll (continuous lines) and 34\% (w/w) sucrose (dotted lines) at $5^{\circ} \mathrm{C}$. Dashed lines mark the hyperfine splitting and are included to aid comparisons. Arrows in the overlay panels indicate spectral differences at the low-field regions. $(A) \mathrm{KQ}-$ 5R1b; (B) KQ-20R1b; (C) ER-20R1b. supports the conclusion that the observed multiple EPR spectral components originate from different C-fragment conformations of the bound N-peptide. As X-band EPR studies report on peptide behaviors at the $0.3-20$ nsec regime (see above), distinct spectral components indicate that these different $\mathrm{C}$-fragment conformations persist as discrete states at the nanosecond or slower timescale.

\section{Characterization of individual spectral components}

To further characterize C-fragment conformations, simulations were carried out in an attempt to extract the individual component spectra at position 20. Simulations use a model that describes nitroxide motions as anisotropic rotational diffusions under a restricted potential (Meirovitch et al. 1984; Budil et al. 1996; Earle and Budil 2006; Khairy et al. 2006). Figure 5 shows simulation results for KQ-20R1b spectra obtained in $30 \%(\mathrm{w} / \mathrm{v})$ and $20 \%(\mathrm{w} / \mathrm{v})$ Ficoll. In both cases, the experimental spectra cannot be simulated with one nitroxide population, but instead can be adequately simulated with two nitroxide populations. The resulting individual component spectra share the same characteristic lineshape: Component A (Fig. 5, green lines) shows splittings at the low-field and high-field regions, while component B shows the three-line pattern of a nitroxide with high mobility (Fig. 5, blue lines). The linewidths of the individual component spectra differ between these two sets, reflecting differences in solution viscosity due to the use of $30 \%$ vs. $20 \%$ Ficoll. Furthermore, the fraction of component A (the low-mobility component), $\mathrm{R}_{\mathrm{lm}}$, is very close between the two sets of simulations $(67 \%$ vs. $64 \%$, Fig. 5 ).

It is known that obtaining a unique, exact fit to an EPR spectrum is difficult (Columbus et al. 2001; Zhang et al. 2010). However, the two sets of simulations for KQ-20R1b gave consistent $R_{l m}$ values and lineshape characteristics, suggesting that the resulting component spectra may reflect intrinsic features of KQ peptide conformations. Specifically, component A (Fig. 5, green lines) shows characteristics of a nitroxide undergoing anisotropic rotations at a surface site of an $\alpha$-helix (Columbus et al. 2001). Its feature is consistent with the proposed stacked state in the dynamic two-state model (Fig. 1E), where the peptide $\mathrm{C}$-fragment forms an $\alpha$-helix that contacts the RNA primarily via Trp18/A7 stacking. Component B (Fig. 5, blue lines) reveals a high-mobility state and is consistent with the proposed unstacked state (Fig. 1E), where the $\mathrm{C}$-fragment is peeled away from the boxB RNA and possibly becomes unstructured. With these assignments, the population fraction of the stacked state is reported by $\left\langle\mathrm{R}_{\mathrm{Im}}>\right.$ of $\sim 66 \%$, which is higher than the $30 \%-50 \%$ values obtained from 2AP decay measurements of the KQ peptides (Supplemental Fig. S1). We note that in order to detect site-specific features in the $8-\mathrm{kDa} \mathrm{N}$-peptide/boxB complex, EPR measurements were performed at a lower temperature $\left(5^{\circ} \mathrm{C}\right)$ than that used 
A
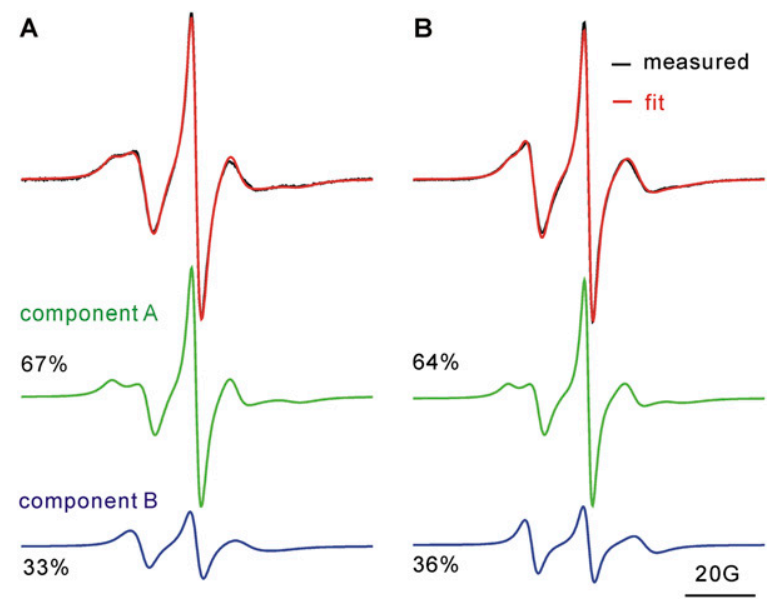

FIGURE 5. Simulations of KQ-20R1b with two nitroxide populations. (A) KQ-20R1b in 30\% (w/v) Ficoll; (B) KQ-20R1b in 20\% (w/v) Ficoll. Simulated best fit spectra are shown in red and are superimposed on the respective measured spectra (black lines). Individual component spectra are shown as green (component A) and blue (component B) lines, respectively. The percentage of each component was derived from scaling factors obtained from simulations, and was verified by double integrations of the respective component spectra. Parameters used to generate the best fit spectra are listed in Supplemental Table S1.

in ultrafast fluorescence studies (room temperature), and a higher fraction of the stacked state may be expected.

Similar to the KQ-20R1b case, the ER-20R1b spectrum (Fig. 3D) cannot be satisfactorily simulated with only one nitroxide population. However, the ER-20R1b spectrum shows a depressed low-mobility component (Fig. 3D and results described above), and a large number of twopopulation simulations can match the measured spectrum to a very similar degree. Consequently, with the ER peptide, it is very difficult to assess the simulation results and extract physical insights from them.

\section{DISCUSSION}

A combination of SDSL and X-band EPR spectroscopy was used to reveal different behaviors of peptide $\mathrm{N}$ - and C-fragments within the N-peptide/boxB complex at the nanosecond regime. The results support the dynamic twostate model of N-peptide/boxB recognition, which was previously proposed based on studies monitoring picosecond fluorescence decay of labels attached to the boxB RNA (Xia et al. 2003a, 2005).

A key finding is that EPR spectra of labels at the Cfragment (position 20), particularly with the wild-type KQ peptide, contain multiple spectral components (Fig. 3). Osmolyte perturbation experiments reveal that these spectral components originate from multiple (i.e., at least two) C-fragment conformations of the bound peptide that are in slow exchange at the nanosecond timescale (Fig. 4). This experimentally demonstrates that conformational hetero- geneity of the N-peptide/boxB complex, which is the cornerstone of the dynamic two-state model, persists in the nanosecond regime. Our result is also consistent with a recent report on the highly analogous bacteriophage P22 N-peptide/boxB complex, in which 20-nsec molecular dynamics simulations revealed reversible conformational transitions at the C-fragment of the bound peptide (Bahadur et al. 2009).

Furthermore, several observations suggest that features of the C-fragment EPR spectra are consistent with characteristics of the stacked and unstacked states postulated in the dynamic two-state model (Fig. 1E). First, the $\mathrm{E}_{14} \mathrm{R}_{15}$ mutation, which has previously been shown to tilt the equilibrium toward the unstacked state (Supplemental Fig. S1; Xia et al. 2003a, 2005), results in a reduction of the lowmobility spectral component that represents the stacked state (Fig. 3). Second, for the R1b probe, lineshapes of the individual spectral components obtained via simulations are in agreement with characteristics of the stacked and unstacked states (see Results section on Fig. 5). Last but not least, sucrose was observed to increase the low-mobility spectral component (Fig. 4). This is consistent with the expectation that sucrose would favor the stacked state, which is likely more compact and less solvent accessible than the unstacked state.

Another aspect of the two-state model is that the Nfragment anchors the peptide to the boxB RNA in both the stacked and unstacked states (Fig. 1E). This is directly supported by EPR data presented here. In the NMR structure of the complex between the boxB RNA and the KQ peptide, the $\mathrm{N}$-fragment forms an $\alpha$-helix that is stably docked into the major groove of the RNA stem (Legault et al. 1998). This accounts for the lower nitroxide mobility observed at KQ-5 (Fig. 3). Importantly, the $\mathrm{E}_{14} \mathrm{R}_{15}$ mutation, which significantly alters the equilibrium between the stacked and unstacked states (Supplemental Fig. S1; Xia et al. 2003a, 2005), does not change EPR spectra at position 5 (Fig. 3). This indicates that the $\mathrm{N}$-fragment conformation remains the same in the stacked and unstacked states.

While spin labels provide information on N-peptide conformations, details regarding bound peptide structure in each of the state remain elusive. Due to the short length of the $\mathrm{N}$-peptide and the presence of a tightly coupled protein/RNA interface, suitable labeling sites are limited, rendering it difficult to conduct a full nitroxide scanning on the complex. Nonetheless, the EPR data reveal that peptide C-fragment is at equilibrium between at least two discrete states that are in slow-exchange in the nanosecond regime, and the population distribution between these states is significantly altered by the $\mathrm{E}_{14} \mathrm{R}_{15}$ mutation. These results suggest that the dynamic two-state model (Xia et al. 2003a, 2005) is applicable to account for peptide conformational features detected at the nanosecond regime. This demonstrates a connection between picosecond and nanosecond dynamics in the N-peptide/boxB RNA complex. 
High-resolution structures are available for N-peptide/ boxB complexes from bacteriophage $\lambda$ (Legault et al. 1998; Schärpf et al. 2000), P22 (Cai et al. 1998), and Phi21 (Cilley and Williamson 2003), as well as for the functionally equivalent Nun/boxB complex from HK022 (Faber et al. 2001). Based on their similar structural features, it has been proposed that the $\mathrm{N}$-peptide/boxB RNA interface provides a conserved docking site for the host factor NusA in antitermination function (Cilley and Williamson 2003). The precise mechanism, however, has eluded researchers for decades (Greenblatt et al. 1993). We have demonstrated that bacteriophage $\lambda \mathrm{N}$-peptide/boxB complex exists in two states at the interface, and the fraction of the stacked state is critical for the anti-termination function (Xia et al. 2003a, 2005). Such dynamic conformational transitions may exist for the other $\mathrm{N}$-peptide/boxB interfaces and impact their functions. It has been speculated that sensing of these conformational distributions, perhaps mediated by NusA, could be a key in N-protein dependent transcriptional antitermination function (Xia et al. 2003b; Xia 2008). As such, information on dynamic conformational distributions and transitions at the RNA/protein interface at different timescale is one of the critical factors in understanding the mechanism of transcription regulation as well as other processes that involve protein/RNA interaction. Obtaining such information requires a combination of techniques that are capable of probing dynamic processes at different time regimes, as demonstrated by studies presented here.

\section{MATERIALS AND METHODS}

\section{Materials}

Nitroxide spin label precursor (1-Oxyl-2,2,5,5-tetramethyl- $\Delta 3$ pyrroline-3-methyl)-methanethiosulfonate was purchased from Toronto Research Chemicals, and (1-Oxyl-2,2,4,5,5-pentamethyl$\Delta 3$-pyrroline-3-methyl)-methanethiosulfonate was provided by Dr. K. Hideg (University of Pécs, Hungary). N-peptides were synthesized by University of Texas Southwestern Medical Center Peptide Chemistry Center, and unmodified and 2AP modified boxB RNAs were obtained from Dharmacon, Inc. All chemicals were purchased from Sigma-Aldrich unless otherwise stated.

\section{Spin labeling and purification of $\mathrm{N}$-peptides}

$\mathrm{N}$-peptides, each containing a single mutated cysteine residue, were incubated with fourfold molar excess of nitroxide precursors overnight at room temperature in a Tris- $\mathrm{NaCl}$ buffer $(100 \mathrm{mM}$ Tris, $\mathrm{pH}$ 6.8, $50 \mathrm{mM} \mathrm{NaCl}$ ). The labeled peptides were purified by reverse-phase HPLC on a C18 column (Alltech Biotechnology) using the following gradient: buffer A, $5 \%(\mathrm{v} / \mathrm{v})$ acetonitrile and $0.045 \%(\mathrm{v} / \mathrm{v})$ trifluoroacetic acid (TFA) in water; buffer B, 100\% acetonitrile; gradient, $0 \%-30 \%$ buffer B in $30 \mathrm{~min}$. The purified spin-labeled peptides were recovered by lyophilization, re-suspended in the Tris- $\mathrm{NaCl}$ buffer, then either used immediately or stored at $-80^{\circ} \mathrm{C}$. The concentration of peptide was determined by UV absorbance at $280 \mathrm{~nm}$ with an extinction coefficient of $5810 \mathrm{~cm}^{-1} \mathrm{M}^{-1}$.

\section{Purification of boxB RNA}

The boxB RNAs were purified by anion-exchange HPLC using protocols that were previously published (Qin et al. 2007). The purified samples were desalted using a reverse-phase C18 column, lyophilized, and then dissolved in the Tris- $\mathrm{NaCl}$ buffer. RNA concentrations were determined according to absorbance at $260 \mathrm{~nm}$ using an extinction coefficient of $147,900 \mathrm{~cm}^{-1} \cdot \mathrm{M}^{-1}$.

\section{Preparation of N-peptide/boxB complex for EPR measurement}

Unmodified boxB RNA was first heated at $95^{\circ} \mathrm{C}$ for 2 min then flash-cooled on ice. Following a 30-min incubation on ice, the annealed RNA was combined with spin-labeled peptide in the Tris- $\mathrm{NaCl}$ buffer at a 1.2:1 ratio (final concentration: RNA $120 \mu \mathrm{M}$, peptide $100 \mu \mathrm{M}$ ). The mixture was incubated at $5^{\circ} \mathrm{C}$ overnight to form the RNA-peptide complex. Proper amount of stock solution of Ficoll (Ficoll 70, 60\% w/v in the Tris- $\mathrm{NaCl}$ buffer) or sucrose $(60 \% \mathrm{w} / \mathrm{w}$ in the Tris- $\mathrm{NaCl}$ buffer $)$ was then added to the reaction mixture to obtain EPR samples that contain $\sim 50 \mu \mathrm{M}$ of spin-labeled complex and the desired amount of Ficoll or sucrose.

\section{EPR spectral acquisition and analysis}

EPR spectroscopy was performed on a Bruker EMX spectrometer that is equipped with an ER-041X microwave bridge and a highsensitivity cavity (ER-4119HS, Bruker Biospin, Inc.). Samples of $5 \mu \mathrm{L}$ were placed in a round glass capillary $(0.6 \mathrm{~mm} \mathrm{ID}, 0.8 \mathrm{~mm}$ OD; Vitrocom, Inc.) sealed at one end. All spectra were acquired at $5^{\circ} \mathrm{C}$ with the following acquisition parameters unless otherwise stated: $2 \mathrm{~mW}$ microwave power, $1.5 \mathrm{G}$ modulation amplitude, $100 \mathrm{kHz}$ modulation frequency, and $100 \mathrm{G}$ scan width. The measured spectra were averaged, baseline corrected, and normalized following published procedures (Zhang et al. 2009). Spectral simulations were carried out with the EPRLL program suite (Earle and Budil 2006) using the microscopic ordering macroscopic disorder (MOMD) model (Budil et al. 1996; Khairy et al. 2006). A Labview-based version of the program was used, which was kindly provided by the Hubbell group at UCLA.

\section{Steady-state fluorescence titration}

In order to assess the influence of spin label on complex formation, titration experiments were performed to measure the dissociation constant $\left(K_{\mathrm{d}}\right)$ of each complex. Samples of boxB RNA was annealed by heating at $95^{\circ} \mathrm{C}$ for $2 \mathrm{~min}$ in a low salt buffer (20 mM Tris-acetate, $50 \mathrm{mM}$ potassium acetate, $\mathrm{pH}$ 7.5), followed by flash-cooling on ice. Fluorescence titration experiments were conducted by monitoring the change in fluorescence of a $2 \mathrm{AP}$ probe incorporated into the RNA, upon titration of nonlabeled or R1b-labeled N-peptides. Titrations were carried out at $20^{\circ} \mathrm{C}$ on a Shimadzu spectrofluorophotometer (RF-5301PC) equipped with a temperature control module where the sample was constantly stirred during data collection. Excitation and emission wavelengths are $310 \mathrm{~nm}$ and $370 \mathrm{~nm}$, respectively. $K_{\mathrm{d}}$ values were determined by fitting to a one-to-one binding isotherm using the DynaFit program (Kuzmic 1996). The standard-state free energy of $\mathrm{N}$-peptide/boxB complex formation was calculated as 


$$
\Delta \mathrm{G}^{\circ}=\mathrm{RT} \ln \left(K_{d}\right)
$$

where $\mathrm{R}$ is the gas constant $\left(\mathrm{R}=1.986 \mathrm{cal} \cdot \mathrm{K}^{-1} \cdot \mathrm{mol}^{-1}\right)$ and $\mathrm{T}$ is the absolute temperature ( $\mathrm{T}=293 \mathrm{~K}$ in this work).

\section{SUPPLEMENTAL MATERIAL}

Supplemental material can be found at http://www.rnajournal.org.

\section{ACKNOWLEDGMENTS}

Research supported by NIH (GM069557, P.Z.Q.), NSF (MCB 054652, P.Z.Q.), the THECB Norman Hackman Advanced Research Program (009741-0015-2007, T.X.), and the Robert A. Welch Foundation (AT-1645, T.X.).

Received July 9, 2010; accepted September 11, 2010.

\section{REFERENCES}

Al-Hashimi HM, Walter NG. 2008. RNA dynamics: It is about time. Curr Opin Struct Biol 18: 321-329.

Altenbach C, Flitsch SL, Khorana HG, Hubbell WL. 1989. Structural studies on transmembrane proteins. 2. Spin labeling of bacteriorhodopsin mutants at unique cysteines. Biochemistry 28: 78067812.

Austin RJ, Xia T, Ren J, Takahashi TT, Roberts RW. 2002. Designed arginine-rich RNA-binding peptides with picomolar affinity. J Am Chem Soc 124: 10966-10967.

Austin RJ, Xia T, Ren J, Takahashi TT, Roberts RW. 2003. Differential modes of recognition in N peptide-boxB complexes. Biochemistry 42: 14957-14967.

Bahadur RP, Kannan S, Zacharias M. 2009. Binding of the bacteriophage P22 N-peptide to the boxB RNA motif studied by molecular dynamics simulations. Biophys J 97: 3139-3149.

Barrick JE, Takahashi TT, Ren J, Xia T, Roberts RW. 2001. Large libraries reveal diverse solutions to an RNA recognition problem. Proc Natl Acad Sci 98: 12374-12378.

Budil DE, Lee S, Saxena S, Freed JH. 1996. Nonlinear-least-squares analysis of slow-motion EPR spectra in one and two dimensions using a modified Levenberg-Marquardt algorithm. J Magn Reson A 120: 155-189.

Burd CG, Dreyfuss G. 1994. Conserved structures and diversity of functions of RNA-binding proteins. Science 265: 615-621.

Cai Z, Gorin A, Frederick R, Ye X, Hu W, Majumdar A, Kettani A, Patel DJ. 1998. Solution structure of P22 transcriptional antitermination N peptide-box B RNA complex. Nat Struct Biol 5: 203-212.

Cantor CR, Schimmel PR. 1980. Biophysical chemistry. W.H. Freeman, San Francisco, CA.

Cilley CD, Williamson JR. 1997. Analysis of bacteriophage N protein and peptide binding to boxB RNA using polyacrylamide gel coelectrophoresis (PACE). RNA 3: 57-67.

Cilley CD, Williamson JR. 2003. Structural mimicry in the phage phi21 N peptide-boxB RNA complex. RNA 9: 663-676.

Cléry A, Blatter M, Allain FHT. 2008. RNA recognition motifs: Boring? Not quite. Curr Opin Struct Biol 18: 290-298.

Columbus L, Kalai T, Jeko J, Hideg K, Hubbell WL. 2001. Molecular motion of spin labeled side chains in alpha-helices: Analysis by variation of side chain structure. Biochemistry 40: 3828-3846.

Das A. 1993. Control of transcription termination by RNA-binding proteins. Annu Rev Biochem 62: 893-930.

Draper DE. 1999. Themes in RNA-protein recognition. J Mol Biol 293: 255-270.
Earle KA, Budil DE. 2006. Calculating slow-motion ESR spectra of spin-labeled polymers. In Advanced ESR methods in polymer research (ed. S Schlick), pp.53-83. John Wiley, New York.

Edwards TE, Robinson BH, Sigurdsson ST. 2005. Identification of amino acids that promote specific and rigid TAR RNA-Tat protein complex formation. Chem Biol 12: 329-337.

Faber C, Schärpf M, Becker T, Sticht H, Rösch P. 2001. The structure of the coliphage HK022 Nun protein- $\lambda$-phage boxB RNA complex. J Biol Chem 276: 32064-32070.

Fanucci GE, Cafiso DS. 2006. Recent advances and applications of site-directed spin labeling. Curr Opin Struct Biol 16: 644-653.

Flores Jimenez RH, Do Cao MA, Kim M, Cafiso DS. 2010. Osmolytes modulate conformational exchange in solvent-exposed regions of membrane proteins. Protein Sci 19: 269-278.

Galiano L, Blackburn ME, Veloro AM, Bonora M, Fanucci GE. 2009. Solute effects on spin labels at an aqueous-exposed site in the flap region of HIV-1 protease. J Phys Chem B 113: 1673-1680.

Greenblatt J, Nodwell JR, Mason SW. 1993. Transcriptional antitermination. Nature 364: 401-406.

Hubbell WL, Altenbach C. 1994. Investigation of structure and dynamics in membrane proteins using site-directed spin labeling. Curr Opin Struct Biol 4: 566-573.

Khairy K, Budil D, Fajer P. 2006. Nonlinear-least-squares analysis of slow motional regime EPR spectra. J Magn Reson 183: 152159.

Kuzmic P. 1996. Program DYNAFIT for the analysis of enzyme kinetic data: Application to HIV proteinase. Anal Biochem 237: 260-273.

Legault P, Li J, Mogridge J, Kay LE, Greenblatt J. 1998. NMR structure of the bacteriophage $\lambda \mathrm{N}$ peptide/boxB RNA complex: Recognition of a GNRA fold by an arginine-rich motif. Cell 93: 289-299.

Leulliot N, Varani G. 2001. Current topics in RNA-protein recognition: Control of specificity and biological function through induced fit and conformational capture. Biochemistry 40: 79477956.

Lopez CJ, Fleissner MR, Guo Z, Kusnetzow AK, Hubbell WL. 2009. Osmolyte perturbation reveals conformational equilibria in spinlabeled proteins. Protein Sci 18: 1637-1652.

Luby-Phelps K, Castle PE, Taylor DL, Lanni F. 1987. Hindered diffusion of inert tracer particles in the cytoplasm of mouse 3T3 cells. Proc Natl Acad Sci 84: 4910-4913.

Lunde BM, Moore C, Varani G. 2007. RNA-binding proteins: Modular design for efficient function. Nat Rev Mol Cell Biol 8: 479-490.

McHaourab HS, Lietzow MA, Hideg K, Hubbell WL. 1996. Motion of spin-labeled side chains in T4 lysozyme. Correlation with protein structure and dynamics. Biochemistry 35: 7692-7704.

Meirovitch E, Nayeem A, Freed JH. 1984. Analysis of protein-lipid interactions based on model simulations of electron spin resonance spectra. J Phys Chem B 88: 3454-3465.

Mogridge J, Legault P, Li J, Van Oene MD, Kay LE, Greenblatt J. 1998. Independent ligand-induced folding of the RNA-binding domain and two functionally distinct antitermination regions in the phage $\lambda$ N protein. Mol Cell 1: 265-275.

Patel DJ. 1999. Adaptive recognition in RNA complexes with peptides and protein modules. Curr Opin Struct Biol 9: 74-87.

Qin PZ, Hideg K, Feigon J, Hubbell WL. 2003. Monitoring RNA base structure and dynamics using site-directed spin labeling. Biochemistry 42: 6772-6783.

Qin PZ, Haworth IS, Cai Q, Kusnetzow AK, Grant GP, Price EA, Sowa GZ, Popova A, Herreros B, He H. 2007. Measuring nanometer distances in nucleic acids using a sequence-independent nitroxide probe. Nat Protoc 2: 2354-2365.

Schärpf M, Sticht H, Schweimer K, Boehm M, Hoffmann S, Rosch P. 2000. Antitermination in bacteriophage $\lambda$. The structure of the N36 peptide-boxB RNA complex. Eur J Biochem 267: 2397-2408.

Sowa GZ, Qin PZ. 2008. Site-directed spin labeling studies on nucleic acid structure and dynamics. Prog Nucleic Acid Res Mol Biol 82: 147-197. 
Su L, Radek JT, Hallenga K, Hermanto P, Chan G, Labeots LA, Weiss MA. 1997. RNA recognition by a bent $\alpha$-helix regulates transcriptional antitermination in phage $\lambda$. Biochemistry 36: 12722-12732.

Van Gilst MR, Rees WA, Das A, von Hippel PH. 1997. Complexes of $\mathrm{N}$ antitermination protein of phage $\lambda$ with specific and nonspecific RNA target sites on the nascent transcript. Biochemistry 36: 15141524.

Weiss MA, Narayana N. 1998. RNA recognition by arginine-rich peptide motifs. Biopolymers 48: 167-180.

Williamson JR. 2000. Induced fit in RNA-protein recognition. Nat Struct Biol 7: 834-837.

Xi X, Sun Y, Karim CB, Grigoryants VM, Scholes CP. 2008. HIV-1 nucleocapsid protein $\mathrm{NCp} 7$ and its RNA stem loop 3 partner: Rotational dynamics of spin-labeled RNA stem loop 3. Biochemistry 47: 10099-10110.

Xia T. 2008. Taking femtosecond snapshots of RNA conformational dynamics and complexity. Curr Opin Chem Biol 12: 604-611.

Xia T, Becker HC, Wan C, Frankel A, Roberts RW, Zewail AH. 2003a. The RNA-protein complex: Direct probing of the interfacial recognition dynamics and its correlation with biological functions. Proc Natl Acad Sci 100: 8119-8123.
Xia T, Frankel A, Takahashi TT, Ren J, Roberts RW. 2003b. Context and conformation dictate function of a transcription antitermination switch. Nat Struct Biol 10: 812-819.

Xia T, Wan C, Roberts RW, Zewail AH. 2005. RNA-protein recognition: Single-residue ultrafast dynamical control of structural specificity and function. Proc Natl Acad Sci 102: 13013-13018.

Yu C, Gabriele V. 2005. Protein families and RNA recognition. FEBS J 272: 2088-2097.

Zhang Z, Xi X, Scholes CP, Karim CB. 2008. Rotational dynamics of HIV-1 nucleocapsid protein NCp7 as probed by a spin label attached by peptide synthesis. Biopolymers 89: 1125-1135.

Zhang X, Cekan P, Sigurdsson ST, Qin PZ. 2009. Studying RNA using site-directed spin-labeling and continuous-wave electron paramagnetic resonance spectroscopy. Methods Enzymol 469: 303-328.

Zhang Z, Fleissner MR, Tipikin DS, Liang Z, Moscicki JK, Earle KA, Hubbell WL, Freed JH. 2010. Multifrequency electron spin resonance study of the dynamics of spin labeled T4 lysozyme. J Phys Chem B 114: 5503-5521.

Zhou HX, Rivas G, Minton AP. 2008. Macromolecular crowding and confinement: Biochemical, biophysical, and potential physiological consequences. Annu Rev Biophys 37: 375-397. 

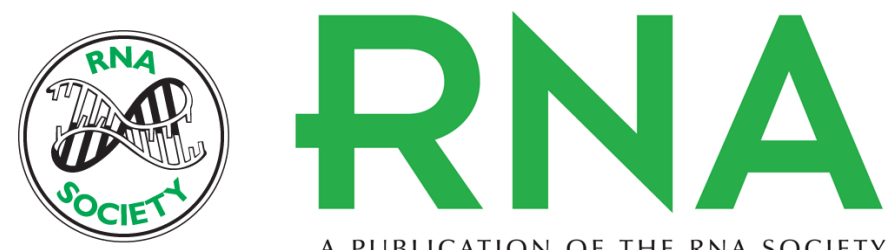

A PUBLICATION OF THE RNA SOCIETY

\section{Conformational distributions at the N-peptide/boxB RNA interface studied using site-directed spin labeling}

Xiaojun Zhang, Sang Won Lee, Liang Zhao, et al.

RNA 2010 16: 2474-2483 originally published online October 27, 2010

Access the most recent version at doi:10.1261/rna.2360610

\section{Supplemental http://rnajournal.cshlp.org/content/suppl/2010/10/18/rna.2360610.DC1 \\ Material}

References This article cites 51 articles, 8 of which can be accessed free at:

http://rnajournal.cshlp.org/content/16/12/2474.full.html\#ref-list-1

\section{License}

Email Alerting Receive free email alerts when new articles cite this article - sign up in the box at the Service top right corner of the article or click here.

\section{||I||||| Providing Precise Solutions for your research.}

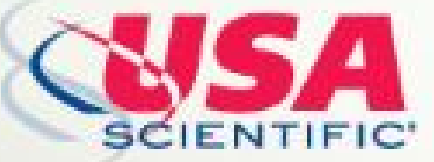

To subscribe to $R N A$ go to:

http://rnajournal.cshlp.org/subscriptions 